\title{
When Modern Technologies Meet Ageing Workforces: Older Workers are more affected by Demands from Mobile Interruptions than their Younger Counterparts
}

\author{
Stefan Tams \\ HEC Montréal \\ stefan.tams@hec.ca
}

\author{
Varun Grover \\ Clemson University \\ vgrover@clemson.edu
}

\author{
Jason Thatcher \\ Clemson University \\ jthatch@clemson.edu
}

\author{
Manju Ahuja \\ University of Louisville \\ manju.ahuja@louisville
}

\begin{abstract}
Mobile technologies have dramatically increased the number of work-related interruptions. In many organizations, employees have to remain accessible and respond to these technology-mediated (T-M) interruptions even after regular work hours. Thus, demands from work interruptions might spill over into workers' evening and family time, entailing role stress. Ultimately, workers might shy away from using the technologies they deem responsible, with negative impacts for organizations. At the same time, the workforce is ageing rapidly, and older workers might be even more susceptible to the negative impacts of interruptions than their younger counterparts. Hence, this research examines whether demands from $T-M$ interruptions reduce IT use indirectly via workers' experiences of role stress and whether this indirect effect depends on age such that it is stronger for older workers. Data collected from 121 younger and 124 older knowledge workers supported this idea. Implications for research and practice are discussed.
\end{abstract}

\section{Introduction}

Organizations rely progressively more upon mobile information technologies to increase their employees' work performance. Mobile technologies, in turn, have dramatically increased the number of work-related interruptions, exposing employees to an endless stream of email notifications, instant messages, and the like, all mediated via smartphones and tablets that constantly beep, buzz, and blink. Estimates suggest that these instant messages and related technologymediated (T-M) interruptions have grown to consume about a third of employees' work days [1]. Studies show that on average, knowledge workers are interrupted every three minutes by such distracting technologies as email notifications and instant messaging [2].
Interruptions frequently come during non-work hours. According to Kleiner Perkins Caufield \& Byers' annual report, over 75 per cent of people unlock their work phones and actively use them during the peak evening time, that is, between $5 \mathrm{pm}$ and $8 \mathrm{pm}$. During this peak evening time, the average person is interrupted nine times every hour by a work-related mobile device. This time period is also the peak family time, implying that the active usage of the work phone during this time is bound to create a strain on family life, entailing role-based stress (i.e., stress from the work role intruding into the family role).

Attending to interruptions can shift attention away from a task, thereby impede task performance and the ability to resume the original task at hand [3]. Thus, we argue that T-M interruptions are likely to create a chain of responses in employees, leading to job-related and behavioral outcomes. Specifically, we suspect that role stress may eventually lead employees to withdraw from using mobile technologies $[4,5,6,7]$. For example, employees experiencing role stress may limit their interactions with coworkers or customers. This limited interaction may result in a decline in the work-related usage of mobile technologies, creating a backlash and a negative reaction to technologies. Hence, this study holds that some of the characteristics of technology that are generally experienced negatively, such as frequent interruptions, can reduce the extent to which people are willing to use the technology. This idea is based on the behavioral theory of operant conditioning, proposing that stimuli that produce a negative outcome (e.g., stress or conflict) are likely to lessen/decrease a behavior (e.g., using a system). Further, this idea is consistent with DeLone and McLean's [8] IS success model and with the technology-acceptance model $[9,10]$, both of which indicate that the characteristics of a technology influence the degree to which it is used.

Overall, our first goal is to examine the potential negative impacts of technology-mediated (T-M) interruptions on individuals and organizations. Regarding organizations, Burton-Jones and Straub [11] have argued that it is crucial for IS research to 
examine work-related IT usage as an outcome variable. In line with this argument, IS research has examined issues of IT use at all levels of analysis, including the individual, the group, and the organizational level [12]. This attention devoted to IT usage is also consistent with Benbasat and Zmud's [13] claim that IS research should focus directly on the use of the IT artifact since IT has to be used so that individuals and organizations can reap its benefits. Hence, examining the impact of technostress on technology usage is important, and it is a logical continuation of research into technostress (technostress is defined as the stress people experience in response to using technologies [5]). ${ }^{1}$ Consistent with this idea, recent technostress research has called for theorizing usage-related, behavioral outcome variables in technostress research (in addition to the psychological outcomes that have been the focus of much prior technostress research) [5,14]. Only few IS studies have followed this call, looking at social support in a hedonic use context (i.e., Facebook [15]). Research needs to build on this pioneering work by examining the work context and the spillover effects that modern, mobile technologies might create (i.e., the work life spilling over and intruding into peoples' personal lives). Such research could yield an enriched understanding of role-based stress and related impacts on IS use in the context of mobility (and the interruptions that mobile devices mediate).

When probing the impacts of demands from T-M interruptions on role stress and IT use, it is important to take into consideration the fact that interruptions and their impacts on employee behavior (e.g., system use) could be far more pronounced for older workers than for their younger counterparts [16]. At the same time, age is considered a "key demographic variable" for IS research [17, p. 469], and recent IS studies have called for examining more closely the role that age plays in IS adoption and use as well as in technostress $[5,18,19]$. Such investigations appear particularly relevant given that the workforce is aging rapidly; in fact, the workforce is said to be graying [20]. According to the OECD, all of its current thirty-four member countries are experiencing rapid population and workforce aging [20,21,22]. The number of older workers has increased by more than $50 \%$ between the years 2000 and 2012 across the OECD countries [23].

As workers age, cognitive and biological changes occur. These changes include the reduced ability to ignore interruptions and remain concentrated on an activity [24]. In the context of mobility, older workers might be at a particular disadvantage. As Sara J. Czaja,

\footnotetext{
${ }^{1}$ In the context of this study with its focus on interruptions, we use the term technostress consistent with prior technostress research on interruptions, such as Galluch et al. [37].
}

professor of psychiatry and behavioral sciences as well as director of the center on research and education for aging and technology at the University of Miami, puts it: "there are a lot of older people who have a lot of trouble with mobile phones" [16, p. 20]. As a result of cognitive and biological changes, older workers are more at risk of being affected by technological stressors in general, and interruptions mediated by mobile devices in particular [16]. Yet, little research explores the challenges involved in the trends toward a graying workforce on the one hand, and ever more modern and complex information technologies on the other [17]. Such research could help improve older workers' well-being and IT use behaviors and, thus, merits more attention (see Table 1, which also identifies closely-related research needs). Hence, our second goal is to explore whether the indirect effect of demands from interruptions on technology use via rolebased stress might depend on worker age.

\section{Table 1. Potential for adding value to research on technostress and IS Use}

\begin{tabular}{|c|c|c|}
\hline $\begin{array}{c}\text { Current State of } \\
\text { Knowledge }\end{array}$ & $\begin{array}{l}\text { Potential to build on } \\
\text { current knowledge }\end{array}$ & $\begin{array}{c}\text { Refe- } \\
\text { rences }\end{array}$ \\
\hline $\begin{array}{c}\text { Mobile devices have } \\
\text { been described as } \\
\text { important creators of } \\
\text { technostress because } \\
\text { they enable "anytime } \\
\text { anyplace" } \\
\text { access through } \\
\text { constant connectivity, } \\
\text { with demands from } \\
\text { interruptions intruding } \\
\text { into employees' } \\
\text { personal lives (that is, } \\
\text { spillover effects) }\end{array}$ & $\begin{array}{l}\text { Creating an enriched } \\
\text { understanding of the } \\
\text { precise effects of mobile } \\
\text { devices, and of the } \\
\text { interruptions they mediate, } \\
\text { on stress and behavioral } \\
\text { consequences. The } \\
\text { demands from interruptions } \\
\text { and their impacts on role } \\
\text { conflict and role stress (i.e., } \\
\text { spillover effects) should be } \\
\text { specifically modeled and } \\
\text { measured }\end{array}$ & 1,14 \\
\hline $\begin{array}{l}\text { Technology usage has } \\
\text { been described to be } \\
\text { an important } \\
\text { consequence of } \\
\text { technostress, but } \\
\text { recent research } \\
\text { called for studies that } \\
\text { explicitly model this } \\
\text { relationship }\end{array}$ & $\begin{array}{c}\text { Generating a refined } \\
\text { understanding of the precise } \\
\text { effects of technostress on } \\
\text { technology usage by } \\
\text { specifically modeling and } \\
\text { measuring these variables } \\
\text { (i.e., providing enriched } \\
\text { theoretical and empirical } \\
\text { support) }\end{array}$ & 7,14 \\
\hline $\begin{array}{c}\text { Individual } \\
\text { differences, such as } \\
\text { age, have primarily } \\
\text { been modeled as } \\
\text { control variables with } \\
\text { simple, direct effects } \\
\text { on technostress or IS } \\
\text { use (e.g., as so-called } \\
\text { "inhibitors") }\end{array}$ & $\begin{array}{c}\text { Limited knowledge as to } \\
\text { whether technostress } \\
\text { effects on IS use depend } \\
\text { on individual differences, } \\
\text { such as age (i.e., } \\
\text { moderation effects showing } \\
\text { for whom technostress } \\
\text { crystallizes and for whom it } \\
\text { manifests in certain } \\
\text { outcomes, such as IS use) }\end{array}$ & $\begin{array}{c}5,6,14 \\
18,25,26\end{array}$ \\
\hline
\end{tabular}


The paper proceeds as follows. The next section provides the study background and probes the hypotheses for our research objective, indicating that demands from T-M interruptions affect the workrelated use of mobile devices via workers' experiences of role stress and that this indirect effect will be more pronounced for older workers. Thereafter, we discuss the large-scale survey employed to collect the data and the data analysis, which supported the model. We conclude with implications for research and practice.

\section{Background and Hypotheses}

We build on prior work by integrating the concepts of T-M interruptions, stress, work-related technology usage, and age. Only few studies have looked at the intersection of two such areas, and no study to date has examined the point at which all these areas intersect. Yet, this intersection holds strong potential to explain how the usage-related impacts of T-M interruptions unfold and how they might depend on worker age. According to recent ideas, T-M interruptions are pertinent to both stress and IS use, stress is a major inhibitor of various work-related behaviors such as IS use behaviors, and older people tend to be far more at risk from interruptions [6,16,19,27].

\section{Demands from T-M Interruptions}

T-M interruptions are prevalent in today's work environments as they occur in various forms, for example, as instant messages, email notifications, task reminders, and message reminders. Given the prevalence of these interruptions and their generally negative consequences for various work-related behaviors, more IS research into the effects of T-M interruptions is warranted [28]. Few studies in IS have focused on the negative consequences of interruptions.

Consistent with Speier et al. [28], we examine T-M interruptions as stressors that are externally generated and randomly occurring and that break continuity of cognitive focus on another activity or obligation. Further, T-M interruptions insist on action so that an individual who is being interrupted generally needs to turn his or her attention toward the interruption (unless a conscious decision is being made to ignore the interruption) [28]. Hence, individuals receiving more $\mathrm{T}-\mathrm{M}$ interruptions than they can effectively process generally consider these interruptions demanding, leading them to perceive that they have too much to do [28]. In line with this notion, in this study we focus on the negative consequences of demands from T-M interruptions. These demands from T-M interruptions can, ultimately, result in stress [1].

\section{Role-based Stress as a Pertinent Problem in the Context of T-M Interruptions}

Given the pervasive, omnipresent nature of such contemporary mobile technologies as smartphones and of the interruptions they mediate, their impacts often transcend work and non-work settings so that peoples' work roles intrude into and interrupt their other roles, creating conflict among the various different role requirements [5,19]. For this reason and consistent with prior research [5,19], we conceptualize stress in response to T-M interruptions as role-based stress in the form of inter-role conflict. Such stress is experienced under conditions of contradictory, incompatible, or incongruent role requirements that occur when a person is asked to fulfill the requirements from multiple roles at the same time [5,19]. Role-based stress in the form of inter-role conflict most frequently manifests as conflicting demands of work and family [4,5,19], implying a conflict about the allocation of time and attention to both environments [4]. For example, it has become common practice for employees to continue to be available after leaving work and even at home [1]. This trend has started when employees became able to check their voicemails on the road and from home, and it grew even more pervasive when employees accessed their emails and other messages on the road and from home [1].

The pervasiveness of work-related interruptions even at home leaves people saddled with conflict between responding to the plethora of work-related queries, questions, and comments and fulfilling their family responsibilities. This inter-role conflict leads them to believe that they have lost control over their time and space, entailing role-based stress $[6,19]$. Tarafdar et al. [7] report on the case of Mike, a Fortune 100 executive, who spends a large part of his annual vacation responding to interruptions from mobile technologies rather than focusing on his family. As a result, Mike overlooks family duties like dinner plans, entailing a major conflict between his job and family roles that may, subsequently, lead him to withdraw from using mobile technologies altogether $[4,6,7]$.

\section{Connecting T-M Interruptions and Role-based Stress to Work-related Technology Usage}

The organizational stress literature suggests that stress varies with the job demands placed on an individual and that stress, in turn, impacts employee behavior [29]. This notion implies for the present paper that high demands from T-M interruptions impact work-related technology usage via increases in rolebased stress. This idea is consistent with prior research that has suggested, albeit not explicitly modeled or 
empirically examined, that demands from T-M interruptions can lead people to shy away from using the technologies that create the interruptions [27,28]. This negative impact of T-M interruptions on usage has been suggested to occur because interruptions are often considered intrusive and are, thus, experienced negatively, resulting in stress that leads people to attempt to escape from them [28] (also see Table 2).

\section{Table 2. Construct Definitions}

\begin{tabular}{|c|l|}
\hline Construct & \multicolumn{1}{c|}{ Definition } \\
\hline $\begin{array}{c}\text { Demands from } \\
\text { T-M } \\
\text { Interruptions }\end{array}$ & $\begin{array}{l}\text { The extent to which individuals perceive that they } \\
\text { have too much to do because they receive more } \\
\text { technology-mediated interruptions than they can } \\
\text { effectively process }\end{array}$ \\
\hline $\begin{array}{c}\text { Role-based } \\
\text { Stress }\end{array}$ & $\begin{array}{l}\text { The inter-role conflict that occurs as job demands } \\
\text { interfere with the performance of family duties }\end{array}$ \\
\hline $\begin{array}{c}\text { Work-related } \\
\text { Technology } \\
\text { Usage }\end{array}$ & $\begin{array}{l}\text { The extent (in terms of intensity and scope) to } \\
\text { which individuals utilize a mobile technology }\end{array}$ \\
\hline
\end{tabular}

Further, technostress researchers have suggested, albeit not explicitly modeled or empirically examined, that T-M interruptions can lead to stress in individuals by breaking peoples' concentration on another activity or obligation [5,19]. For example, Mike overlooks family duties like dinner plans even during vacation time due to the demands from T-M interruptions [7], a case that indicates a major conflict between job and family roles, creating role-based stress [4,5,7]. More generally, in today's fast-paced environment the omnipresence of work-related T-M interruptions even at home leaves employees saddled with conflict between responding to the plethora of work-related queries, questions, and comments and fulfilling their primary family responsibilities, entailing role-based stress [5,19]. In fact, mobile technologies frequently even accompany holidays, and one often feels that one has to respond to e-mail from home, even if this behavior entails role-conflict [1,19]. Thus, role-based stress due to T-M interruptions is a common, although understudied, phenomenon [5,19].

Role-based stress in the form of inter-role conflict has downstream negative consequences for job-related employee behaviors [4]. People in high conflict roles tend to show less trust, liking, and respect for the object they deem responsible for the conflict they experience [4]. As a result, they withdraw from the object, or they limit their interactions with it [4]. Hence, the role-based stress resulting from the T-M interruptions that are mediated by mobile technologies may lead people to withdraw from using mobile technologies, or it may lead them to restrict their interactions with them. In either case, the work-related usage of mobile technologies is expected to decline due to the role-based stress experienced on the basis of demands from T-M interruptions. This notion is akin to DeLone and McLean's [8] IS success model and to the technology-acceptance model [10], both of which indicate that the characteristics of a technology can impact the extent to which it is used. The idea is based on the behavioral theory of operant conditioning, proposing that stimuli that produce a negative outcome (stress or conflict in this case) are likely to lessen/decrease a behavior (using the system). Hence:

H1: Role-based stress mediates the negative effect of demands from $T$ - $M$ interruptions on work-related technology usage, that is, there is a negative, indirect effect of demands from T-M interruptions via rolebased stress on work-related technology usage.

We are not proposing direct effects here because our focus is on how and why demands from T-M interruptions reduce work-related technology usage (via role-based stress), implying an indirect effect.

\section{Examining Differences across Age Groups}

Recent inquiry into aging and technology suggests that interruptions and their impacts on employee behavior (e.g., IT use) could be far more pronounced for older workers than for their younger counterparts [16]. At the same time, age is considered a "key demographic variable" for IS research [10, p. 469], and recent IS studies have called for examining more closely the role that age plays in IS adoption and use as well as in technostress $[5,18,19]$. Such investigations appear particularly relevant given the rapid workforce ageing or "graying" [20]. Importantly, the trend toward an older workforce will continue into the future; the participation of older people in the workforce is expected to increase sharply over the next several decades across the OECD member countries [20].

We ground our exploration of age differences (regarding workers' responses to demands from interruptions) in the literatures on cognition and cognitive aging [30]. These literatures highlight the importance of working memory to our study context. Working memory is a transitory storage and processing component in the brain that holds the information required for carrying out a given activity (that is, a personal or work-related activity; [30]). As a case in point, once a phone number has been found on a Web site, it is held in working memory until it is fully dialed [30]. Importantly, the capacity of working memory is severely limited, at times to just one single piece of information [30]. Given this rigid capacity limitation, T-M interruptions can easily interfere with the information processing related to a given personal or job-related activity when they enter working memory. This is because interruptions draw working memory resources away from an activity, leaving fewer 
resources for the processing of information related to the activity (note that interrupting stimuli enter working memory simply when people attend to them). As a result, mental work on the activity becomes slow and error-prone (e.g., slow and incorrect dialing of phone numbers or slow reading and writing), leading to stress and subsequent behavioral consequences (e.g., reduced usage of a mobile device; [30]).

To avoid stress by ensuring that only information related to a current personal or job-related activity enters working memory, human cognition relies on selective attention [30]. Selective attention refers to the capacity to attend selectively to relevant information sources while ignoring others; it is concerned with the allocation of processing resources. An important mechanism of selective attention is the inhibitory mechanism [30]. The inhibitory mechanism of selective attention filters out irrelevant stimuli, helping people remain concentrated on a given activity. Effective inhibition entails that people deliberately disregard any distracting stimuli in their environment. Inhibition is goal-directed; people with effective inhibition can purposefully ignore an interruption when they have the goal of remaining concentrated and focused on a given activity. However, the effectiveness of attentional inhibition differs considerably across individuals, primarily as a function of age [30,31].

Research on cognitive aging examines the changes in working memory and selective attention that come about with age [31]. We draw on the inhibitory deficit theory of cognitive aging, which describes how and why age impacts the active control of the contents of working memory [31]. This theory is a major theoretical approach to aging, having received widespread empirical support [30]. The inhibitory deficit theory indicates that attentional inhibition is impaired in older people. This impairment is due to age-related changes that occur in the frontal lobe, which is the brain section that houses the inhibitory mechanism of selective attention [31]. As people age, the frontal lobe's connections to other sections in the brain deteriorate, and the frontal lobe shrinks. These structural deteriorations in the frontal lobe entail corresponding corrosions in the inhibitory mechanism (because the inhibitory mechanism is housed in the frontal lobe). It is these corrosions in the inhibitory mechanism that lead to the inhibitory deficit that older individuals generally demonstrate [31]. Hence, in older compared to younger people, interruptions are more likely to gain access to working memory and to interfere with the information processing related to a given activity [31]. This interference implies that the progress people make on their main activities is slowed and error-prone, leading them to be stressed and, in the end, to avoid the behaviors they deem responsible (e.g., being interrupted by a mobile device).

In sum, we maintain that T-M interruptions can be problematic because of the capacity limitation of working memory. Yet, an effective inhibitory mechanism of selective attention can buffer against the negative consequences of interruptions by preventing them from entering working memory in the first place. The inhibitory mechanism is, principally, a protective shield against interruptions. Yet, inhibition is impaired in older individuals, leaving them less protected. Thus, we hypothesize that the indirect effect of demands from interruptions on technology use via role-based stress should be stronger for older workers:

H2: The strength of the mediated relationship between demands from T-M interruptions and workrelated technology usage (via role-based stress) depends on a worker's age; the negative, indirect effect of demands from T-M interruptions via role-based stress on work-related technology usage will be stronger for older workers than for their younger counterparts.

\section{Method and Results}

Data were collected from knowledge workers who had to use mobile technologies for their work after regular work hours (consistent with, e.g., [14]). Following recent IS research [25], a market research company was used for data collection. Market research companies aim for providing researchers with samples representative of the general population [25]. To this end, they carefully construct large databases of panel members, who are profiled over many attributes, such as job title, industry, and income [25]. Further, these companies employ sophisticated quality assurance mechanisms, such as the verification of demographic information provided by panel members against validated consumer databases, quality assurance questions embedded in the surveys, and the identification of fraudulent acts [25]. These mechanisms together with the employment of relevant screening heuristics prevent sampling and statistical conclusion errors by ensuring that researchers have full access to a well-defined sample frame and can acquire an adequate sample size [25].

In this study, we used the market research division of SurveyMonkey that has recently acquired Zoomerang. SurveyMonkey's market research division was a particularly appropriate market research company for the purpose of our study since the use of mobile technologies and of the internet belong to its most popular targeting criteria, implying that SurveyMonkey is specialized on providing survey 
responses to studies like ours (www.surveymonkey.com). Furthermore, SurveyMonkey's market research division has access to over 30 million panel members (www.surveymonkey.com). As part of the panel member recruitment process, SurveyMonkey asks prospective panel members to complete a detailed profile survey, and SurveyMonkey verifies that prospective panelists are who they say they are. This verification process includes the verification of respondents against third-party databases, the validation of email and postal addresses, and the testing of whether the panelists' responses are sound (e.g., SurveyMonkey uses data mining methods to compare panelists' stated income levels to their professions) (www.surveymonkey.com). SurveyMonkey also ensures through careful maintenance of its panel that respondents are qualified to answer surveys. For example, it removes unserious survey takers and implements knowledge-based questions that define whether a respondent is qualified to take a survey. Further, SurveyMonkey limits the number of surveys that its members can take per week to ensure that no one member is over-participating, and SurveyMonkey's reward structure discourages panelists from rushing through surveys. Additionally, SurveyMonkey conducts regular benchmarking studies to ensure that its panel members are representative of the general population (www.surveymonkey.com).

To satisfy sample frame requirements, four screening heuristics were developed. First, prospective respondents had to use mobile devices for their work. Second, they had to engage in skilled knowledge work (e.g., sales, technology). Third, they had to be a "younger" or "older" worker in accordance with our operationalization of age as discussed below. Finally, respondents had to be accessible through mobile technologies after regular work hours. The first three heuristics were collected by SurveyMonkey as part of their panel dataset. The fourth heuristic was obtained through a screening question that respondents had to answer. By using these four heuristics, we sampled a representative population of skilled knowledge workers who had the opportunity for experiencing role stress.

The respondents were queried regarding the demands from work-related T-M interruptions they experience after regular work hours, their experiences of role-based stress in the form of inter-role conflict, and the extent to which they used their mobile technologies for work. All measures were adapted from prior research [e.g., 11,32; see Appendix 1].

As regards worker age, we operationalized this concept in a way consistent with prior IS research on age and with the inhibitory deficit theory of cognitive aging by comparing chronologically younger to older workers [31,33]. We relied on OECD definitions to define worker age: younger workers were defined as those between 16 and 29 years of age, whereas older workers were defined as those between 50 and 64 years of age (i.e., before retirement age, [23]). In aging research, the group of 50 to 64 years old is often referred to as the "young-old" and, as such, differentiated from more advanced age groups such as the "middle-old" and the "old-old" [31]. We defined older workers as belonging to the group of the "youngold" (i.e., before retirement age) so as to make sure that our results would be widely generalizable.

The quality of our survey instrument was assessed by estimating the reliability and construct validity of the measurement items. SPSS version 21 was used to calculate all statistics, which evidenced good measurement properties. All alphas exceeded the 0.7 threshold, all AVE values were above 0.50, and the square root of the AVE for each construct was higher than the correlations between that construct and all other constructs in the model. Further, we used both procedural and statistical remedies to control for method bias (e.g., we protected respondent anonymity, reduced evaluation apprehension, and evaluated the significance of common method variance in our data by performing Harmon's single factor test) [34]. No method bias was detected.

Since the instrument exhibited good measurement properties, we proceeded with a formal test of our hypotheses using the bootstrapping procedure developed by Preacher and Hayes [35]. More specifically, both hypotheses were assessed using Hayes' PROCESS macro for testing indirect effects in SPSS [36]. For Hypothesis 1, we employed PROCESS model number 4 with a $95 \%$ confidence interval and 1,000 bootstrap resamples in SPSS version 21 to the full sample $(\mathrm{n}=245)$. The results supported Hypothesis 1: a significant, negative indirect effect of demands from T-M interruptions on work-related technology usage via role-based stress was found $(b=-0.366$, $\mathrm{SE}=0.115, \mathrm{LL}=-0.604, \mathrm{UL}=-0.148, \mathrm{p}<0.05)$.

To test Hypothesis 2, we subdivided our data into two groups (younger and older workers). The two groups had comparable sample sizes, 121 younger and 124 older workers. In the group of younger workers, the mean age was 24 years, the minimum age was 18 years, and the maximum was 28 years (standard deviation $=3$ years). In the group of older workers (the "young-old"), the mean age was 56 years, the minimum age was 50 years, and the maximum was 64 years (standard deviation $=5$ years). We calculated the indirect effect of demands from T-M interruptions on work-related technology usage via role-based stress in each of the two groups. As was the case for Hypothesis 1, we calculated these effects using Hayes' PROCESS macro for testing indirect effects in SPSS [36]. The 
analyses were conducted by employing PROCESS model number 4 with a $95 \%$ confidence interval and 1,000 bootstrap resamples. The results supported our predictions: the indirect effect was not significant in the sub-sample of younger workers $(b=-0.173$, $\mathrm{SE}=0.190, \mathrm{LL}=-0.637, \mathrm{UL}=0.165, \mathrm{p}>0.05)$, but it was significant for older workers $(b=-0.326$, $\mathrm{SE}=0.139, \mathrm{LL}=-0.614, \mathrm{UL}=-0.079, \mathrm{p}<0.05)$.

For older workers, the model explained $49 \%$ of the variance in role-based stress and $38 \%$ of the variance in work-related technology use which, given the few predictor variables in our model, compares favorably to much prior IS use research. Hence, our model is both parsimonious and powerful, important criteria for contributing to knowledge.

Consistent with the inhibitory deficit theory, these results evidenced that older workers are more affected by demands from T-M interruptions than their younger counterparts, in terms of reduced usage of their mobile devices in response to role-based stress.

\section{Implications}

By providing a conceptualization and empirical evaluation of the roles of mobility and demands from $\mathrm{T}-\mathrm{M}$ interruptions in technostress and IS use, the present study extends related research and theory. Specifically, although T-M interruptions have been recognized in the practitioner literature as an important problem [1], IS research is just beginning to examine the potential negative impacts of such interruptions on individuals and organizations. Although some studies $[14,19]$ have described T-M interruptions as a potential source of technostress, they have not focused on interruptions per se but have, rather, discussed them along with other sources of technostress (for an exception, see [37]). As a result of this broad approach, prior research has seldom specifically theorized and measured demands from T-M interruptions, limiting what we know about interruption-based stress. Our work extends prior research by offering a more detailed and specific examination of the role of T-M interruptions in technostress. Specifically, the present study builds on prior works' conceptualizations of T-M interruptions as stressors [14,37] to theorize that demands from T-M interruptions impact work-related technology usage-a key outcome variable in IS research [11]-through creating inter-role conflict (i.e., a specific form of role-based stress).

Further, given rapidly aging workforces across the OECD member countries and recent calls for examining the role of age in technostress and IS use $[18,19]$, this study tested whether Hypothesis 1 yields different results for younger and older workers. The results showed that the indirect effect of demands from
T-M interruptions on work-related technology usage via role-based stress crystallizes for older workers but not for younger ones. This finding offers a refined understanding of the applicability of technostress theory in the contexts of mobility and interruptions, indicating to whom the problems regarding demands from interruptions are applicable. This notion contextualizes the technostress phenomenon and its consequences for IS use. We used the inhibitory deficit theory of cognitive aging [31] to theorize that older workers are more affected by T-M interruptions than their younger counterparts due to an impaired inhibitory mechanism of selective attention.

Systems designers could assist older adults in more effectively handling T-M interruptions by designing different types of interruptions in such a way that they all appear in the same (i.e., fixed) location on the screen as opposed to different locations. Research has shown that predictability of spatial location can offset the large disadvantage that older people have in inhibiting attentional responses to interruptions. For example, in the current version of Skype (i.e., 4.2.0.169), VoIP phone calls and instant messages, which are different types of T-M interruptions, appear in different locations on the display. While VoIP phone calls appear in the center, instant messages appear on the bottom of the screen. If Skype were re-designed such that both types appeared on the bottom, older workers could better inhibit an immediate response to either interruption type since they could better predict where interruptions will appear on the screen. Please see Table 3 for a summary of this study's value-added to research on technostress and IS use. Importantly, our study results should not be used to encourage discrimination against older workers but to facilitate interventions that can increase the well-being and productivity of a graying workforce. 
Table 3. Value-added of this research

\begin{tabular}{|c|c|c|c|}
\hline $\begin{array}{c}\text { General } \\
\text { contributions } \\
\text { of the } \\
\text { Present Study }\end{array}$ & $\begin{array}{l}\text { Specific Value- } \\
\text { Added of the } \\
\text { Present Study }\end{array}$ & $\begin{array}{c}\text { Practical } \\
\text { Implications } \\
\text { of the } \\
\text { Present } \\
\text { Study } \\
\end{array}$ & $\begin{array}{l}\text { Refe- } \\
\text { rences }\end{array}$ \\
\hline $\begin{array}{c}\text { Explicit } \\
\text { conceptualizati } \\
\text { on and } \\
\text { empirical } \\
\text { evaluation of } \\
\text { the role of } \\
\text { mobility in the } \\
\text { technostress } \\
\text { and IS use } \\
\text { phenomena, } \\
\text { including the } \\
\text { spillover } \\
\text { effects that } \\
\text { mobility } \\
\text { creates such } \\
\text { that work spills } \\
\text { over into } \\
\text { peoples' } \\
\text { personal lives }\end{array}$ & \begin{tabular}{|c|} 
Enriched \\
theoretical and \\
empirical \\
understanding of \\
the important role \\
that interruptions \\
mediated by \\
mobile devices \\
play in the \\
technostress \\
phenomenon and \\
of their predictive \\
power in this \\
context. Enriched \\
understanding of \\
how demands \\
from interruptions \\
intrude into and \\
spill over into \\
peoples' \\
personal lives
\end{tabular} & $\begin{array}{c}\text { Managers } \\
\text { must be } \\
\text { aware of the } \\
\text { "dark side" of } \\
\text { interrupting } \\
\text { mobile } \\
\text { technologies } \\
\text { for worker } \\
\text { health, and } \\
\text { they should } \\
\text { adjust } \\
\text { related } \\
\text { corporate } \\
\text { policies and } \\
\text { norms }\end{array}$ & 1,14 \\
\hline $\begin{array}{c}\text { Establishing } \\
\text { work-related } \\
\text { technology } \\
\text { usage as an } \\
\text { important } \\
\text { consequence } \\
\text { of stress from } \\
\text { interruptions }\end{array}$ & $\begin{array}{c}\text { Enriched } \\
\text { theoretical and } \\
\text { empirical } \\
\text { understanding of } \\
\text { how technological } \\
\text { stressors, such as } \\
\text { T-M interruptions, } \\
\text { impact work- } \\
\text { related technology } \\
\text { usage, } \\
\text { demonstrating } \\
\text { that technological } \\
\text { stressors can } \\
\text { reduce such } \\
\text { usage }\end{array}$ & $\begin{array}{c}\text { Managers } \\
\text { must be } \\
\text { aware of the } \\
\text { important role } \\
\text { of } \\
\text { technostress } \\
\text { in negatively } \\
\text { impacting } \\
\text { usage } \\
\text { behaviors and } \\
\text { of ways to } \\
\text { counteract } \\
\text { this impact }\end{array}$ & 7,14 \\
\hline $\begin{array}{c}\text { Conceptualizati } \\
\text { on and } \\
\text { empirical } \\
\text { evaluation of } \\
\text { the role of age } \\
\text { in the } \\
\text { technostress } \\
\text { and IS use } \\
\text { phenomena, } \\
\text { with an } \\
\text { emphasis on } \\
\text { mobility and } \\
\text { interruptions }\end{array}$ & \begin{tabular}{|c} 
A refined \\
understanding of \\
to whom \\
technostress \\
theory is \\
applicable; thus, \\
contextualizing the \\
technostress \\
phenomenon and \\
its consequences \\
(e.g., IS use). \\
Demonstrating that \\
age plays an \\
important role in \\
technostress
\end{tabular} & \begin{tabular}{|} 
Managers \\
need to \\
develop \\
greater \\
sensitivity for \\
the \\
importance of \\
individual \\
differences, \\
especially \\
age, for the \\
effective use \\
of IT, \\
especially in \\
interruption- \\
intensive \\
workplace \\
designs
\end{tabular} & $\begin{array}{c}5,6,14 \\
18,25,26\end{array}$ \\
\hline
\end{tabular}

\section{Limitations and Conclusion}

As with any research, there are some limitations that should be considered when interpreting our results. Perhaps most importantly, future research may include additional control variables, such as "time spent with family" or family commitment, amongst others.

Considering the proliferation of interruptions that are mediated by mobile technologies, it is important for IS research to offer practitioners a deeper understanding of the potential "dark sides" of these T$\mathrm{M}$ interruptions, such as diminished worker health and work-related IT use. Although a few prior studies have described the potential drawbacks of T-M interruptions, they have not modeled or measured the negative impacts of these interruptions in terms of spillover effects. The present study found that demands from work-related T-M interruptions after regular work hours reduce work-related use by inducing role-based stress in the form of inter-role conflict. We believe that this study takes an important step toward clarifying the role of demands from T-M interruptions in technostress and toward illustrating the role of technostress in IT usage. The latter contribution is particularly important given that technology usage is considered a key outcome variable in IS research and given that prior technostress research has called for an examination of the impacts of technological stressors on IS usage.

Besides, our analyses demonstrated that demands from interruptions are particularly problematic for older workers (the so-called "young-old"), in terms of reduced IT usage in response to role-based stress. Given the facts that the workforce is rapidly growing older across all OECD member countries and that modern technologies such as interruptions are proliferating, our findings are alarming. Yet, the findings should not be construed as encouraging discrimination against older workers or as encouraging any kind of stereotyping. Instead, they should be considered a means of facilitating the development of intervention strategies that can increase the well-being and productivity of a graying workforce. Managerial interventions and technological developments are needed that offset the weaknesses and leverage the strengths of older workers to improve their well-being and increase organizational productivity. Accordingly, more work is needed in this important area.

\section{Acknowledgements}

This research was supported by the Social Sciences and Humanities Research Council of Canada. 


\section{References}

[1] Spira, J. B., \& Feintuch, J. B. (2005). The cost of not paying attention: How interruptions impact knowledge worker productivity Basex.

[2] Fried, I. (2005). Driven to distraction by technology In CNET News.com.

[3] Iqbal, S. T., \& Horvitz, E. (2010). Notifications and awareness: A field study of alert usage and preferences. Proceedings of the 2010 ACM Conference on Computer Supported Cooperative Work, 27-30.

[4] McGrath, J. E. (1976). Stress and behavior in organizations. In M. Dunnette (Ed.), (pp. 1351-1395). Chicago: Rand McNally.

[5] Riedl, R. (2013). On the biology of technostress: Literature review and research agenda. The DATA BASE for Advances in Information Systems, 44(1), 18-55.

[6] Riedl, R., Kindermann, H., Auinger, A., \& Javor, A. (2012). Technostress from a neurobiological perspectivesystem breakdown increases the stress hormone cortisol in computer users. Business \& Information Systems

Engineering, 4(2), 61-69.

[7] Tarafdar, M., Tu, Q., Ragu-Nathan, T., \& Ragu-Nathan, B. S. (2011). Crossing to the dark side: Examining creators, outcomes, and inhibitors of technostress. Communications of the ACM, 54(9), 113-120.

[8] DeLone, W. H., \& McLean, E. R. (1992). Information systems success: The quest for the dependent variable. Information Systems Research, 3(1), 60-95.

[9] Davis, F. D. (1989). Perceived usefulness, perceived ease of use, and user acceptance of information technology. MIS Quarterly, 319-340.

[10] Venkatesh, V., Morris, M. G., Davis, G. B., \& Davis, F. D. (2003). User acceptance of information technology: Toward a unified view. MIS Quarterly, 27(3), 425-478.

[11] Burton-Jones, A., \& Straub, D. W. (2006). Reconceptualizing system usage: An approach and empirical test. Information Systems Research, 17(3), 228-246.

[12] Sidorova, A., Evangelopoulos, N., Valacich, J. S., \& Ramakrishnan, T. (2008). Uncovering the intellectual core of the IS discipline. MIS Quarterly, 32(3), 467-A20.

[13] Benbasat, I., \& Zmud, R. W. (2003). The identity crisis within the is discipline: Defining and communicating the discipline's core properties. MIS Quarterly, 27(2), 183-194.

[14] Tarafdar, M., Tu, Q., \& Ragu-Nathan, T. (2010). Impact of technostress on end-user satisfaction and performance. Journal of Management Information Systems, 27(3), 303334.
[15] Maier, C., Laumer, S., Weinert, C., \& Weitzel, T. (2015). The effects of technostress and switching stress on discontinued use of social networking services: a study of FB use. Info Systems J, 25, 275-308.

[16] Greengard, S. (2009). Facing an age-old problem. Communications of the ACM (52:9), pp. 20-22.

[17] Venkatesh, V., Morris, M. G., Davis, G. B., \& Davis, F. D. (2003). User acceptance of information technology: Toward a unified view. MIS Quarterly, 27(3), 425-478.

[18] Tams, S., Grover, V., \& Thatcher, J. (2014). Modern information technology in an old workforce: toward a strategic research agenda. The Journal of Strategic Information Systems, 23(4), 284-304.

[19] TARAFDAR, M., QIANG, T. U., RAGU-NATHAN, B., \& RAGU-NATHAN, T. (2007). The impact of technostress on role stress and productivity. Journal of Management Information Systems, 24(1), 301-328.

[20] OECD 2011. Helping older workers find and retain jobs. In Pensions at a Glance 2011: Retirement-Income Systems in OECD and G20 Countries. Paris, France: OECD Publishing, $67-79$.

[21] OECD 2007. The ageing challenge. In Ageing and the Public Service: Human Resource Challenges. Paris, France: OECD Publishing, pp. 17-28.

[22] OECD 2013. OECD Employment Outlook 2013. Paris, France: OECD Publishing. <http://www.oecdilibrary.org/employment/oecd-employment-outlook2013_empl_outlook-2013-en>.

[23] OECD 2016. Labour Market Statistics : Labour force statistics by sex and age. OECD Employment and Labour Market Statistics (Database), DOI : http://dx.doi.org/10.1787/data-00309-en.

[24] Zacks, R., \& Hasher, L. (1997). Cognitive gerontology and attentional inhibition: A reply to burke and McDowd. Journals of Gerontology Series B: Psychological Sciences and Social Sciences, 52B(6), P274

[25] Ayyagari, R., Grover, V., \& Purvis, R. (2011). Technostress: Technological antecedents and implications. MIS Quarterly, 35(4), 831-858.

[26] Ragu-Nathan, T., Tarafdar, M., Ragu-Nathan, B., \& Tu, Q. (2008). The consequences of technostress for end users in organizations: Conceptual development and empirical validation. Information Systems Research, 19(4), 417-433.

[27] Cooper, C. L., Dewe, P. J., \& O'Driscoll, M. P. (2001). Organizational stress: A review and critique of theory, research, and applications. Thousand Oaks, CA US: Sage Publications, Inc. 
[28] Speier, C., Vessey, I., \& Valacich, J. S. (2003). The effects of interruptions, task complexity, and information prese

[29] De Lange, A. H., Taris, T. W., Kompier, M. A., Houtman, I. L., \& Bongers, P. M. (2003). The very best of the millennium": Longitudinal research and the demandcontrol-(support) model. Journal of Occupational Health Psychology, 8(4), 282.

[30] Wickens C. D., Lee J., Liu Y. D., \& Becker, S. G. (2004). Introduction to Human Factors Engineering, NJ: Prentice Hall.

[31] Hasher, L., \& Zacks, R. T. (1988). Working memory, comprehension, and aging: A review and a new view. The psychology of learning and motivation: Advances in research and theory, vol. 22. In G. H. Bower (Ed.), San Diego, CA US: Academic Press, pp. 193-225.

[32] Ahuja, M. K., Chudoba, K. M., Kacmar, C. J., McKnight, D. H., \& George, J. F. (2007). IT road warriors: Balancing work-family conflict, job autonomy, and work overload to mitigate turnover intentions. Mis Quarterly, 31(1), 1-17.

[33] Morris, M. G., Venkatesh, V., \& Ackerman, P. L. (2005). Gender and age differences in employee decisions about new technology: An extension to the theory: Of planned behavior. IEEE Transactions on Engineering Management (52:1), pp. 69-84.

[34] Podsakoff, P. M., MacKenzie, S. B., Lee, J., \& Podsakoff, N. P. (2003). Common method biases in behavioral research: A critical review of the literature and recommended remedies. Journal of Applied Psychology, 88(5), 879-903.

[35] Preacher, K. J., \& Hayes, A. F. (2004). SPSS and SAS procedures for estimating indirect effects in simple mediation models. Behavior Research Methods, Instruments \& Computers, 36(4), 717-731.

[36] Hayes, A. F. (2013). Introduction to mediation, moderation, and conditional process analysis: A regressionbased approach. Guilford Press.

[37] Galluch, P. S., Grover, V., \& Thatcher, J. B. (2015). Interrupting the Workplace: Examining Stressors in an Information Technology Context. Journal of the Association for Information Systems, 16(1), 1.

\section{Appendix 1 - Measurement Items}

\section{We used 7-point likert-type scales ranging from 1 (strongly disagree) to 7 (strongly agree) for most items (except for the two last items measuring work-related technology usage)}

Demands from T-M Interruptions [32]

- I feel overloaded because I receive more interruptions than I can process.

- I feel rushed due to more frequent interruptions.

- I feel busier because I must handle interruptions.

- I feel pressure due to interruptions.

Role-based Stress in the form of inter-role conflict [32]

My use of mobile devices for work results in...

- the demands of my work interfering with my home and family life.

- my job taking up more time and making it difficult to fulfill family responsibilities.

- things I want to do at home do not getting done because of the demands my job puts on me.

- my job producing stress that makes it difficult to fulfill family duties.

- my making changes to my plans for family activities so that I can meet work-related demands.

\section{Work-related Technology Usage [11]}

- How frequently do you access your mobile technology device?

- During a typical day, how many minutes do you spend using your mobile technology device?

- Of all the features and functions available on your mobile technology device, what percentage would you estimate that you use on a fairly regular basis?

- Approximately, what percentage of all your job functions is managed using your mobile technology device? 